Estudios sobre el Mensaje Periodístico

ISSN-e: 1988-2696

http://dx.doi.org/10.5209/ESMP.55591

\title{
Enfoque Estructural Complejo: propuesta metodológica desde el periodismo
}

\author{
Ramón Reig ${ }^{1}$; Rosalba Mancinas-Chávez²; Antonia I. Nogales-Bocio ${ }^{3}$
}

Recibido: 20 de enero de 2016 / Aceptado: 21 de abril de 2016

Resumen. Proponemos la Metodología del Enfoque Estructural Complejo (MENEC) o Enfoque Estructural Complejo (EEC), cuyas raíces se remontan a la filosofía más clásica. Nos basamos en la metodología compleja de Edgar Morin o lo que Konrad Lorenz llamó epistemología comparada. Todo está relacionado con todo y esa relación conforma el Todo Universal o 'Pluriversal'. Desde el Periodismo reivindicamos la Filosofía como el origen de la ciencia y el mejor método para comprender el mundo actual, imposible de concebir — por otro lado - sin la influencia del periodismo.

Palabras clave: Filosofía; comunicación; estructura; complejidad.

\section{[en] Structural Complex approach: methodological proposal from the journalism}

\begin{abstract}
We propose the Methodology of the Structural Complex Approach (MSCA) or Structural Complex Approach (SCA), whose roots go back to the most classical Philosophy. We are based on Edgar Morin's complex methodology or epistemology compared by Konrad Lorenz. Briefly, this methodology thinks that everything is related to everything and that this relation shapes the universal or 'Pluriversal' one. From Journalism we claim Philosophy as the origin of the science and the best way for understand the current world. In the other hand is not possible to conceive this world without journalism.
\end{abstract}

Keywords: Philosophy; communication; structure; complexity.

Sumario. 1. Introducción. 2. Concreción de la hipótesis. 3. La mente crítica como punto de partida metodológico. 4. Resultados; 4.1. Conocimiento Omnisciente; 4.2 Apuntes sobre sus antecedentes y actualidad; 4.3 La Economía Política de la Información, la Comunicación y la Cultura (EPICC). 5. Conclusiones. 6. Referencias bibliográficas.

Cómo citar: Reig, Ramón; Mancinas-Chávez, Rosalba; y Nogales-Bocio, Antonia I. (2017): "Enfoque Estructural Complejo: propuesta metodológica desde el periodismo", en Estudios sobre el Mensaje Periodístico 23 (1), 191-208.

1 Universidad de Sevilla.

E-mail: ramonreig@us.es

2 Universidad de Sevilla.

E-mail: mancinas@us.es

3 Universidad de Sevilla.

E-mail: anogalesb@us.es 


\section{Introducción}

En el amplio mundo de la Comunicación se encuentra la Periodística, es decir, la ciencia que estudia el Periodismo ${ }^{4}$. Y el periodismo contiene a su pieza angular que es la noticia, muy estudiada desde la universidad y con mucho acierto (Miquel Rodrigo Alsina, 1989, Mar de Fontcuberta, 1993). Si continuamos con esta exposición deductiva concluimos con que en la entradilla o lead de la noticia se encuentran, entre otras, las dos preguntas que unen al periodismo con la filosofía y con la ciencia: qué y por qué, es decir, qué ocurre y por qué ocurre lo que ocurre. El cómo ocurre, quién protagoniza lo que ocurre, dónde y cuándo, son interrogantes complementarias de las dos interrogantes de la noticia a las que, en este trabajo, consideraremos como cruciales: qué y por qué.

Comunicación, Ciencia y Periodismo se hallan pues unidos por la Filosofía, todo lo cual nos lleva a lo que llamaremos pensamiento transversal o enfoque/método estructural (Mancinas-Chavez, 2008, Reig, 2001, Reig, 2010 y Reig, 2011a). Lo que pretendemos con estas líneas es demostrar cómo el pensamiento filosófico es de enorme utilidad para entender lo que acontece en el mundo en general y en particular en el vasto sector del conocimiento teórico-práctico aplicado a la Comunicación, vista desde el propio enfoque estructural (Nogales-Bocio, 2015).

Dicho enfoque, lleva, a su vez, en su seno, una submetodología llamada Economía Política de la Información, la Comunicación y la Cultura (EPICC), de manera que poco a poco se va configurando esa visión complejo-deductiva que intenta explicarse "lo que ocurre", las viejas interrogantes de nuestro sentido y significado como especie, sólo que este método total/estructural se puede parcelar sin perder por ello la idea de Totalidad Absoluta de la que se derivaría "lo demás".

El interés por las relaciones entre Filosofía, Comunicación y Periodismo por supuesto no es nuevo. Carmen Herrero Aguado (1991) escribió sobre "Filosofía de la Comunicación" de forma muy esquemática, Antonio Sánchez-Bravo Cenjor (1992) ha acudido a Nietzsche para explicar estructura de la información. María Jesús Casals (2005) ha analizado textos de Aristóteles cuando desarrollaba su exposición sobre la narrativa periodística. Pero no conocemos una aplicación que desde el Periodismo nos lleve a la máxima complejidad pasando por estadios metodológicos más concretos y acotados, sobre la base de la Filosofía. Esta última vertiente es la que aquí se persigue, ampliando lo que ya se esbozó en otros trabajos (Reig, 2001 y 1999).

\section{Concreción de la hipótesis}

La transversalidad epistemológica se ha vuelto indispensable en Ciencias Sociales y Humanidades para intentar comprender el significado profundo de lo que ocurre en un mundo especialmente complejo. La filosofía no sólo no es una materia marginal sino que posee una potencialidad enorme para el análisis teórico-metodológico a partir de las preguntas clásicas qué y por qué, contenidas en la entradilla periodística, algo que nos lleva desde el enfoque superficial del periodismo hasta un enfoque estructural más o menos complejo.

4 En España existe la Sociedad Española de Periodística (SEP), véase: http://periodistica.es/v5/ 


\title{
3. La mente crítica como punto de partida metodológico
}

Poco o nada de lo que se acaba de indicar es posible concretarlo sin la presencia de la mente o capacidad crítica. Para definirla vamos a comenzar a recurrir a la Filosofía. El qué y el por qué, en sus planos más hondos, exigen la crítica de los saberes recibidos, según, por ejemplo, la disconformidad de Descartes y su espíritu emprendedor-cognitivo, algo muy importante para explicar también la práctica del Periodismo. No hay periodismo sin capacidad crítica, sin actividad, sin iniciativa, sin observación participante, sin transgresión (Pena de Oliveira, 2006). Descartes, en su Discurso del Método, apunta:

\begin{abstract}
Por ello, tan pronto como la edad me permitió salir de la sujeción de mis preceptores, abandoné completamente el estudio de las letras. Y, tomando la decisión de no buscar otra ciencia que la que pudiera hallar en mí mismo o en el gran libro del mundo, dediqué el resto de mi juventud a viajar, a conocer cortes y ejércitos, a tratar con gentes de diversos temperamentos y condiciones, a recoger diferentes experiencias, a ponerme a mí mismo a prueba en las ocasiones que la fortuna me deparaba, y a hacer siempre tal reflexión sobre las cosas que se me presentaban, que pudiese obtener algún provecho de ellas (Descartes, 1998).
\end{abstract}

Descartes (1596-1650) criticaba las enseñanzas recibidas en su educación escolar debido - decía él - a las numerosas lagunas que presentaban los saberes recibidos. Por tanto, decide buscar un método científico universal mediante la interrelación de varios saberes (física, geometría, álgebra, mecánica...). Después, lo articula todo en su Método que elabora ya consagrado a la Filosofía. Su método se basa en el raciocinio: la evidencia, la comprobación de datos, el análisis y la síntesis. Descartes participa en guerras, viaja muchísimo, habla y trata con personas de todo tipo, he aquí lo relevante (Descartes, 1998: 15 y ss).

Sin mente crítica no existe verdadera ciencia social ni, por tanto, método esencialmente válido de indagación que se diferencie de tanto cuantitativismo y tanto informe técnico que se hace pasar por investigación. La mente crítica lleva al Enfoque Estructural (más o menos complejo) y viceversa. Tampoco se obtienen sin mente crítica unas Humanidades transgresoras ni unas ciencias "puras" y más o menos exactas que se cuestionen a sí mismas y se pregunten por sus significados en lugar de quedarse sólo en un utilitarismo desde luego positivo pero incompleto.

La mente crítica contemporánea posee sus orígenes inmediatos en el pensamiento marxista y en la Escuela de Frankfurt (Muñoz, 2005) aunque, como estamos viendo y veremos, sus raíces son muchísimo más profundas, tan ancestrales como el homo sapiens sapiens, por tanto es absurdo pretender politizarla con el propósito de desprestigiarla y borrarla de la comunidad científica y de la opinión pública aunque los intentos no faltan y han dado muchos frutos como lo demuestra la marginación de la filosofía en los planes de estudios españoles y la incapacidad sincrónica de los jóvenes y adultos de determinados países como Estados Unidos o Inglaterra, algo que exige la implantación universal de la llamada alfabetización mediática:

En Estados Unidos y Alemania, los adolescentes pasan siete horas y media diarias usando medios digitales. [...]. Nuestros chicos cuando elaboran un texto o hacen 
un comentario están poniendo negro sobre blanco sus ideas. Lo que sucede es que en la lectura en pantalla, la lectura profunda es incompleta. El problema es que pasamos demasiado tiempo en ese tipo de lectura y dedicamos menos a la más sosegada. La captura no es la misma cuando lees una página en papel sin interrupciones. En la lectura digital hay una cierta dispersión. Vas de una pantalla a otra, el texto te lleva a un vídeo y luego a un mapa, y la concentración es menor, aunque la cantidad de lectura es mayor. Según los expertos, hay un nuevo fenómeno que afecta cada vez a más personas: la atención parcial continua. Es lo que sucede cuando pasamos mucho tiempo ante una pantalla, que estamos pendientes de muchas cosas, pero sin llegar a solidificar nada. (Pérez-Lanzac, 2013).

Sobre la alfabetización mediática en el caso de España — aplicable a otros países- hay excelentes trabajos como el avalado por varias decenas de profesores de toda España bajo la coordinación de los investigadores Joan Ferrés i Prats (Investigador Principal), Agustín García Matilla, J. Ignacio Aguaded Gómez, Josep Fernández Cavia, Mònica Figueras y Magda Blanes (2011). En él puede leerse:

La alfabetización mediática, entendida de una u otra manera, lleva aparejada la capacidad de comprender y valorar críticamente los diversos aspectos de los diferentes medios de comunicación, consiguiendo filtrar adecuadamente la información recibida a través del torrente de datos y de imágenes y gestionar adecuadamente las emociones que generan. La educación mediática debería formar parte de los planes de estudio en todos los niveles educativos y debería plantearse como objetivo inexcusable alcanzar la competencia mediática de toda la población (Ferrés, 2011: 85-86)

El enfoque estructural hasta sus últimas consecuencias —en cuanto a contenidos y significados - es el gran contexto de la alfabetización mediática y es lo que más nos importa en este trabajo. Pierre Vilar (1981: 51 y ss) reflexiona sobre el concepto "estructura" aplicado a la Historia, pero a una Historia, así, con mayúsculas, algo que se contrapone a los tradicionales, miopes y acotadísimos enfoques del historicismo localista y de "batalla" superestructural.

Primero, Vilar (1981) nos recuerda el origen latino de estructura: "struere" que significa construir. "La imagen querida es, pues, la de un edificio, con su plano, su elevación, sus proporciones calculadas, sus funciones". "De hecho, se trata del reconocimiento de una evidencia: el espíritu humano no puede actuar sobre las cosas (y ha demostrado que era capaz de hacerlo) más que en la medida en que es capaz de reconstruir y de expresar en un lenguaje lógico 'cómo están hechas las cosas'. Si las cosas fueran 'de cualquier manera', si cambiaran de forma incoherente entre una observación y la siguiente, la ciencia no hubiera existido y el hombre no habría llegado a la luna".

El científico se enfrenta al objeto; en nuestro caso, el objeto es el periodismo y sus más profundas circunstancias: pasadas, presentes y futuras (perspectiva histórica, Estructura Real de la Información y la Comunicación bajo el prisma de la Economía Política, y el pensamiento complejo). El objeto es lo observable. "La cosa observada es tal como es", dice Pierre Vilar. Y añade: "Nosotros la observamos, y somos nosotros quienes, a partir de esta observación, construimos un 'modelo' reflejando 
el mayor número posible de características del objeto o, en todo caso, de sus rasgos fundamentales. La prueba del éxito de esta operación la constituye la capacidad de acción sobre el objeto que nos da la construcción del modelo".

De ahí que la ciencia sea "la adecuación — en continuo progreso - de la imagen construida que nos hacemos de la realidad misma. Claro está que la realidad no es cada objeto concreto. Es el conjunto de las características fundamentales de un determinado tipo de objeto, y el conocimiento 'estructural' del conjunto nos permitirá manejar mejor cualquier objeto de este tipo, por comparación con el 'modelo' ideal" (Vilar, 1981) . Es decir, de nuevo la metodología inductivo-deductiva que nos lleva a fijar un punto de partida deductivo, un modelo a partir del cual interpretar los hechos.

El modelo, en nuestro caso, tiende al Todo y por ello esta pretensión ontológica nos lleva a reivindicar a la Filosofía como método para dar sentido profundo al objeto de estudio comunicación-periodismo — que es uno de los elementos de la Historia - bajo un enfoque estructural. "Concebir la unidad de la historia, es decir, pensar la historia universal como un todo, es el impulso que mueve el saber histórico a buscar su último y propio sentido", afirma Karl Jaspers. El filósofo puntualiza y completa así dicha afirmación: "La historicidad del hombre es, desde luego, historicidad múltiple. Pero la multiplicidad está bajo la exigencia de la unidad. Ésta no es, sin embargo, la pretensión exclusivista de una historicidad de ser la única e imponerse a todas las demás, sino que ha de ser desarrollada por la conciencia, en la comunicación de lo que históricamente es múltiple, como la absoluta historicidad de lo uno".

Jaspers coloca las bases de la situación contextual actual en la que se encuentra la comunicación-periodismo con la reflexión que ahora recogeremos, siempre que a la acción de los europeos le añadamos la de Estados Unidos en nuestros días. Así, el filósofo pasa de la discursividad teórica anterior sobre el Todo a la constatación práctica:

Desde el siglo XV, los europeos han encerrado el planeta entero en su red de comunicaciones. Llevaron su civilización a todas partes y se apropiaron bienes de la civilización que no poseían. Llevaron sus animales domésticos, plantas útiles, armas, sus productos y máquinas, sus costumbres y creencias, y toda la desdicha de su mundo, y trajeron las patatas, el maíz, la quinina, el cacao, el tabaco, la hamaca, etc. Ante todo, hicieron a los hombres conscientes de la unidad de la tierra, y al tráfico, planeable, permanente, seguro. Este trato entre los hombres significa su constante amalgamiento, y al unificar el planeta la patentización de la unidad para la conciencia de los hombres y, finalmente para su acción. (Jaspers, 1994: 317-332)

Nuestra metodología pretende "convertir" en una herramienta práctica a la filosofía más allá de ella misma como filosofía práctica (Arnaiz, 2007), con el fin de aplicarla a un enfoque complejo que pueda explicarnos no sólo cómo funciona la comunicación-periodismo sino cómo funciona el devenir evolutivo general que ha generado a la propia comunicación-periodismo. Adaptamos así el qué y el por qué del lead periodístico al ámbito de la indagación académica que es, asimismo, una

Las palabras en cursiva son de los autores, así como las palabras entrecomilladas. 
forma sui generis de ejercer el periodismo y la ciencia que lo estudia: la Periodística. Además, en la práctica, la metodología compleja encierra a la inductiva-deductiva en el sentido de que desde el periodismo podemos llegar al Todo y viceversa.

\section{Resultados}

Conviene dejar muy claro el punto de partida que es el enfoque o método estructural. Para explicarnos qué sucede y por qué sucede lo que sucede — en este caso aplicado a la Comunicación - ya no nos sirve el estructuralismo "clásico" y reduccionista aplicado a parcelas como la Lingüística (Saussure) o a la Antropología (Levi-Strauss). Tampoco nos es totalmente útil el enfoque marxista del materialismo histórico y la dialéctica aunque sí algunas de sus ideas clave como las influencias que el entorno en general generan sobre la conciencia humana o las fases por las que atraviesa la especie en su desenvolvimiento histórico (Marx, 1989, Marx y Engels, 2005).

La aparición y desarrollo de disciplinas como la Física Cuántica, la Biología Molecular, la Genética, la Neurociencia, la Sociobiología, la Psicohistoria o la Etología animal y humana, entre otras, nos obligan a revisar a fondo visiones parciales que no nos dejan ver el bosque en su sentido más profundo. Es necesario comenzar de nuevo, los viejos paradigmas, las filosofías místicas o los enfoques emotivos son inútiles por mucho que determinadas emociones nos hayan servido para llegar hasta donde estamos en la dinámica evolutiva. El humano no puede seguir pugnando entre lo que es y lo que quisiera ser, es preciso que construya una alternativa a partir de lo que es y tal alternativa puede ser indistintamente para vivir, para morir o para quedar moribundo.

El punto de partida es el enfoque estructural o conocimiento transversal. Entre el origen de la materia - por llamar de alguna manera a la génesis de Todo- y el humano hay una relación. Y en medio de dicha relación, múltiples operaciones de causa-efecto han tenido lugar y se seguirán produciendo exista o no el humano.

Lo que se acaba de afirmar nos deja abiertas dos interrogantes, sumergidas en un mar de teorías, empirismos, disgregaciones y elucubraciones: la definición y demostración lo más exacta posible de la condición o naturaleza humana y el papel del azar en el desenvolvimiento de Todo. No es éste el lugar para extendernos sobre el asunto.

\subsection{Conocimiento Omnisciente}

Aportamos basamentos filosóficos como puntos de partida que nos conduzcan a lo que podemos llamar Conocimiento Omnisciente, partiendo de la base de que Conocimiento e Información no son lo mismo sino que Información son las teselas sin ordenar de un mosaico mientras que el Conocimiento es la conformación del mosaico o del puzle, si se desea (Reig, 1995: 265 y ss). Nuestro conocimiento omnisciente es mucho más modesto que el que ofrece el enfoque religioso o teísta. Nosotros nos conformamos — nada menos — con intentar conocer el significado más esencial que encierra la especie humana para procurar ser muy conscientes de la existencia como resultado de una macro-evolución. Estamos en la línea de Erwin Schrödinger:

El conocimiento aislado que ha obtenido un grupo de especialistas en un campo estrecho no tiene en sí mismo valor de ninguna clase. Sólo tiene valor en el sistema 
teórico que lo reúne con todo el resto del conocimiento, y solamente en la medida en que contribuya realmente a responder a la pregunta: “¿Qué somos nosotros?" (Schrödinger, citado en Morin, 2006)

Schrödinger es físico. Edgar Morin (2006) sostiene: "Desde ahora, no sólo hay que articular la esfera antroposocial a la esfera biológica, hay que articular una y otra a la esfera física". Desde luego, este autor matiza mucho el asunto y deja constancia de su dificultad pero la idea transversal está ahí. El astrónomo Juan Pérez Mercader siempre nos recomienda tener en cuenta el mito Uroboros (Pérez Mercader, 2000). Recordemos que dicho mito se representa mediante una serpiente que acaba mordiéndose su propia cola.

El mito Uroboros (parece que de origen egipcio, siglo XXIV a. d. C.) ha sido utilizado por la psicología, la física, la astronomía o por los llamados enfoques esotéricos. Para nosotros no es más que una representación de la Totalidad interrelacionada, es decir, del enfoque estructural en su sentido más complejo y transversal, algo parecido a lo que Konrad Lorenz llamó epistemología comparada (Lorenz, 1974).

El antropólogo estadounidense Marvin Harris (2000), estima que "nuestra tarea como científicos consiste en descubrir el orden en lo que se presenta como desordenado". Por su parte, Karl Popper, en un libro publicado en 1934, nos ofreció su Teoría de los Tres Mundos:

Mundo 1: el mundo de la física: rocas, árboles y los campos físicos de fuerzas; la química y la biología.

Mundo 2: El mundo psicológico. Los sentimientos de temor, esperanza, de las disposiciones a actuar y de todo tipo de experiencias, incluidas las subjetivas e inconscientes.

Mundo 3: El mundo de los productos de la mente humana. Las obras de arte, las instituciones, los valores éticos, las sociedades. Y especialmente los libros, las bibliotecas científicas, los problemas científicos y las teorías, incluidas las científicas (Popper, 1995).

Los autores citados — procedentes de varios campos del saber — van mucho más allá del humano, se diversifican hacia el Todo en mayor o menor medida, he aquí los fundamentos de la Metodología del Enfoque Estructural Complejo/Enfoque Estructural Complejo (MENEC/EEC) como matriz de otros Enfoques Estructurales (EE. EE.) más acotados; he aquí el pensamiento transversal, he aquí el Conocimiento filosófico Omnisciente que proponemos para intentar descifrar una Teoría del Todo y que ella, a su vez, nos conduzca al citado conocimiento, una teoría que nos permita explicarnos el sentido profundo y sustancial de nuestra existencia y/en su contexto más amplio, todo ello desde las Ciencias Sociales y las Humanidades en general y desde las preguntas claves del lead de la noticia periodística, en particular.

\subsection{Apuntes sobre sus antecedentes y actualidad}

¿Dónde hunde sus raíces el Enfoque Estructural Complejo (EEC) y hasta dónde llega en nuestros días? El ser humano lleva siglos planteándose algo similar a los resultados de nuestras pesquisas filosóficas. 
El mundo actual procede en grandísima medida de la cultura grecolatina y de su filosofía, sobre todo de la filosofía clásica griega. Ya sabemos que no pocos filósofos griegos le deben parte de sus postulados a lo que aprendieron en los templos egipcios. Desde Egipto, a través de Grecia, Roma y la cultura filosófica y clásica islámica, nos llega la mayor parte del saber occidental, exportado luego a otros lugares - para bien y para mal - donde en ocasiones ha sido revisado y adaptado. Pero dejémonos de digresiones históricas sincrónicas en esta ocasión y centrémonos primero en los filósofos presocráticos (siglos VI-V a. de C.) para bucear en los antecedentes del enfoque estructural que defendemos. Aquellas mentes preclaras y geniales partían casi de la nada, intentaban superar la fase mitológica humana para sustituirla por la fase de abstracción filosófica. Los resultados fueron asombrosos, he aquí algunos de sus postulados:

— Anaximandro y el Ápeiron. la materia infinita, indeterminada. Ápeiron es un principio sin forma, sin límite y junto con su contrario —el «límite»— constituye la base de todo lo existente.

- Parménides, Empédocles y Demócrito: el intelecto y el alma son una misma cosa.

—Empédocles, Leucipo, Demócrito y Heráclito: antes que los cuatro elementos hay partículas pequeñísimas.

— Inmutabilidad (Parménides) y Cambio (Heráclito) del Ser. (Heráclito et al., 1999)

Todos estos principios - mirados desde la actualidad - contienen un Enfoque Estructural Complejo. La materia infinita nos lleva al origen de Todo, el "límite", a la controversia sobre la extensión del universo. La identidad intelecto-alma desemboca en el título de uno de los libros más conocidos del divulgador de la ciencia Eduardo Punset: El alma está en el cerebro:

Cuando se supo que el alma estaba en el cerebro, se descubrieron las bases de la neurobiología moderna: que funcionamos con un cerebro integrado, que guarda lo esencial de nuestros antepasados los reptiles y los primeros mamíferos, junto a la membrana avasalladora del cerebro de los homínidos, y que están integrados pero no revueltos; es decir, que las comunicaciones entre ellos no son necesariamente fluidas y seguras. Gracias a las nuevas tecnologías de resonancia magnética y otras hemos aprendido a identificar dónde fallan esas señales cerebrales y ahora podemos descubrir cómo funciona un cerebro locamente enamorado o las partes que permanecen inhibidas en la persona incapaz de ponerse en el lugar del otro, como les ocurre a los psicópatas (Punset, 2012).

Antes que los cuatro elementos hay partículas pequeñísimas, afirmaban los atomistas presocráticos. En nuestros días, aún estamos demostrando esta genial intuición. Por ejemplo, la llamada partícula de Higgs. Alicia Rivera escribía en el diario El Pais:

Por fin. Medio siglo después de haberse conjeturado su existencia, se ha descubierto la partícula de Higgs. Y es realmente importante: desde hoy se conoce un poco mejor cómo funciona el universo. Ha hecho falta construir el más potente 
acelerador de partículas, el LHC, dos colosales detectores y el trabajo y entusiasmo de miles de físicos e ingenieros de todo el mundo volcados en la investigación. El Higgs, dicho de modo muy sencillo, ayuda a explicar por qué existe la masa de las partículas elementales. Si el electrón, por ejemplo, no tuviera masa no se formarían los átomos y sin átomos no existirían ni estrellas, ni planetas ni personas. (Rivera, 2012)

Inmutabilidad (Parménides) y Cambio (Heráclito) del Ser. Esta dicotomía tan célebre y conocida nosotros la aplicamos al desarrollo del Poder a lo largo de la Historia Humana. En el desenvolvimiento de su historia, los humanos crean estructuras de Poder, desde la horda hasta las corporaciones empresariales y financieras actuales en las que se incluyen las corporaciones mediáticas con sus medios de comunicación o productos a vender, desde el comic hasta el multimedia y la Inteligencia Artificial (a seguir muy de cerca), pasando por prensa, radio, televisión, cine, libros y firmas ajenas a la comunicación, todo eso es el Poder (Reig, 2011b), completado por el factor político superestructural al que nos referiremos después cuando tratemos sobre la EPICC. La idea de Ser-Estructura permanece substancialmente inmutable (Parménides), lo que cambian son las formas superestructurales/coyunturales del Ser/Poder, o sea, en palabras presocráticas, la base de la llama está ahí, estable, las llamas son las que cambian y hasta desaparecen en apariencia porque siguen siendo átomos.

Si forzamos los principios filosóficos de otros clásicos con el objetivo de obtener más resultados que añadir y así argumentar mejor las raíces de nuestra metodología compleja, llegamos hasta Platón: "Platón distingue dos modos de realidad, una, a la que llama inteligible, la Idea, y que tiene las características de ser inmaterial, eterna, ingenerada e indestructible, ajena al cambio, por lo tanto, y que constituye el modelo o arquetipo de la otra realidad, la sensible, constituida por lo que ordinariamente llamamos cosas, y que tiene las características de ser material, corruptible, (sometida al cambio, pues, a la generación y a la corrupción), y que no es más que una copia de la realidad inteligible" .

La Idea es el hecho histórico "inmutable” estructuras de poder/mediáticas. Las "cosas" son los ropajes, las estrategias, con que las estructuras de poder van adaptando su papel a los tiempos, cambios coyunturales sobre una base ideal, inmutable en su esencia, abstracto-teórica, llamada estructuras de poder/mediáticas que, con los siglos, y de acuerdo con el pensamiento filosófico empirista a partir del siglo XVIII y con la EPICC — que veremos de inmediato - puede demostrarse y concretarse en la realidad que nos circunda y en buena medida nos determina.

Aristóteles nos permite ampliar un poco más nuestra interrelación Filosofía-Estructuras de Poder/Mediáticas porque una de las estrategias que precisa lo "inmutable" para seguir poseyendo tal condición es la catarsis. Las "cosas" cambiantes de Platón incluyen la catarsis de Aristóteles. "Según describía Aristóteles, el miedo, la identificación con el sufrimiento de los personajes y el resto de emociones que inspiraba la tragedia griega lograban una 'catarsis' sobre los espectadores, que quedaban así liberados de sus propios temores. Su alma, decía el filósofo, se purificaba" (Díaz, 2011). Lo inmutable/estructuras de poder/mediáticas, en sus estrategias de conservación (las "cosas" variables) crean elementos (programas de televisión, pelí-

6 http://www.danieltubau.com/biologia/biologia_memes.html. 
culas, telenovelas, videojuegos...) con los que el sujeto lleva a término una catarsis mediante la cual fortifica la inmutabilidad de la Idea, es decir, de las estructuras de poder/mediáticas.

Como vemos, los presocráticos, Platón y Aristóteles, marcan el camino a la actualidad al tiempo que piensan en el Todo. Javier López Facal, investigador del español Consejo Superior de Investigaciones Científicas (CSIC), escribió en un artículo publicado en El País:

Demócrito de Abdera (460-370 a. C.) dejó escrito aquello de que "los principios de todo son los átomos y el vacío; lo demás son meras opiniones”. A un filósofo antiguo le bastaba con postular una hipótesis intrínsecamente coherente o verosímil, y no sentía la necesidad de demostrarla experimentalmente; hoy en día, como estamos tan resabiados y somos bastante más incrédulos, dedicamos miles de millones de euros a construir complicadísimos artefactos que nos permitan demostrar empíricamente la validez de una hipótesis como, sin ir más lejos, la del bosón de Higgs. (López Facal, 2011)

Desde el punto de vista de la física cuántica o de partículas, la Teoría del Todo o teoría unificada fue el sueño incumplido de Einstein. A este empeño dedicó con pasión los últimos treinta años de su vida. No lo logró y hoy continúa sin descubrirse. Consiste en una teoría definitiva, una ecuación única que dé respuesta a todas las preguntas fundamentales del Universo.

Einstein creía que sí existe. Para él, el Universo es algo armónico y ordenado, en el que todo está relacionado y tiene un propósito. Creía en la belleza de las matemáticas y del Universo. Seguía la visión tradicional de los antiguos matemáticos y filósofos griegos. Por eso no aceptó el caos de la cuántica, recién descubierta por aquella época. Para él, "Dios no juega a los dados". Einstein se quedó solo en su búsqueda de una teoría del todo. Durante los últimos años de su vida se distanció tanto de sus colegas que le ridiculizaban y le tomaban por loco. Sin embargo, Stephen Hawking (2007) cree que se logrará esa Teoría del Todo ${ }^{7}$.

\subsection{La Economía Política de la Información, la Comunicación y la Cultura (EPICC)}

Otro de los resultados de nuestra argumentación nos lleva a la EPICC. Recordemos que hemos indicado más arriba que el Enfoque Estructural Complejo (EEC) o Pensamiento Transversal (PT)/, matriz de una metodología articulada del Todo que nos conduzca al Conocimiento Omnisciente, puede ser objeto de acotación sin perder su esencia. Cualquier fenómeno social, económico, psicológico, animal no racional, científico, en general, debe ser analizado bajo una óptica a la vez acotada y matriz.

Nuestra acotación cuando estudiamos la Comunicación la llevamos a cabo mediante la metodología o submetodología EPICC, amplia de por sí y susceptible de ser a su vez delimitada para desarrollar investigaciones parciales o muy particulares sobre la base de otras metodologías para-estructurales. En estos casos estaríamos

Ver: http://science.portalhispanos.com/wordpress/2010/09/08/cientificos-aseguran-poder-probar-la- $\% \mathrm{C} 2 \% \mathrm{ABteoria-}$ del-todo $\% \mathrm{C} 2 \% \mathrm{BB} /$ [consulta: 23 de octubre de 2014]; y:

http://www.astromia.com/astronomia/teoriaunificada.htm [consulta: 23 de octubre de 2014] 
consumando un camino inductivo desde unos métodos más simples que no pierden de vista lo más complejo.

Nosotros ahora - para mostrar más resultados metodológicos y contribuir a la alfabetización mediática - vamos a reducir el Enfoque Estructural Complejo (EEC) y la capacidad crítica a la submetodología EPICC, menos compleja aunque también muy amplia en objetos de estudio. ¿En qué consiste? Lo más habitual es acudir a uno de los autores clásicos y expertos en el tema (Mosco, 2009, 2006) ya que no hay cambios sustanciales en esta corriente metodológica. Lo primero que debemos matizar es que Mosco no utiliza las siglas EPICC (correspondientes a Economía Política de la Información, la Comunicación y la Cultura) sino que habla de The Political Economy of Communicaton, una expresión suficientemente seria y vasta en su contenido aunque, en nuestra opinión, insuficiente si tenemos en cuenta que nosotros partimos de que tenemos en mente el EEC.

No obstante, hay que dejar bien claro que Mosco está pensando no sólo en cuestiones económico-empresariales mediáticas sino en las influencias de los mensajes en los receptores y en determinados estudios culturales que procuran demostrar el influjo de dichos mensajes - procedentes de grandes estructuras mercantiles - en sus destinatarios. Mosco (2006) está convencido "del negocio de la comunicación y el poder de las grandes compañías de comunicación para formar valores y creencias", es decir, en nuestra opinión, para consolidar y/o crear una cultura que favorezca los intereses de esas compañías.

Volvemos a Parménides y Heráclito: el Ser/Estructura de poder se ha caracterizado siempre por precisar de un mensaje que lo legitime, es algo "inamovible", lo movible son las formas coyunturales de actuación o conducta de ese Ser/Estructura así como las reacciones y herramientas "defensivas" de los receptores.

Vayamos pues por partes y constatemos primero algunas ideas de Mosco quien estima, para empezar, que "repensar la economía política también enfatiza el cambio social, los procesos sociales y las relaciones sociales, por encima de la tendencia tradicional en la economía política a partir de las estructuras sociales y las instituciones". A continuación, Vicent Mosco nos ofrece definiciones de Economía Política de la Comunicación de las que destacamos una:

En un sentido estricto, economía política es el estudio de las relaciones sociales, particularmente las relaciones de poder, que mutuamente constituyen la producción, distribución y consumo de recursos, incluidos los recursos de comunicación. Esta formulación tiene un cierto valor práctico porque llama la atención sobre cómo opera el negocio de la comunicación, por ejemplo, cómo los productos comunicacionales transitan a través de una cadena, de productores (como los estudios de Hollywood) a distribuidores, comerciantes y, finalmente, consumidores, cuyas compras, alquileres y atenciones alimentan nuevos procesos de producción. Sin embargo, existe suficiente ambigüedad acerca de lo que constituye un productor, distribuidor o consumidor, como para ser cauteloso con su uso. (Mosco, 2006)

Por supuesto, las tendencias actuales de la Economía Política de la Comunicación no olvidan la sociedad de servicios y la realidad tecnológica existente y tienden "a favorecer puntos de partida filosófico-morales que promueven la extensión de la democracia a todos los aspectos de la vida social. Ello va más allá del reino de la 
política, que garantiza los derechos a participar en el Gobierno, a los dominios económico, social y cultural en los que quienes apoyan la democracia solicitan igualdad en el ingreso, acceso a la educación, y participación pública plena en la producción cultural y una garantía del derecho a comunicarse libremente".

No es éste el lugar para exponer las características de la Economía Política de la Comunicación en los estudios que se han desarrollado y desarrollan en Estados Unidos, Europa o el Tercer Mundo, tal y como los clasifica Mosco. Pero sí podemos apuntar algunas ideas cuando el autor se refiere a "Repensar la Economía Política", antes de pasar a aportar nuestras consideraciones sobre el tema. Coincidimos con las tesis de Mosco cuando indica: "yo desarrollo un mapa sustancial de la economía política con tres procesos de entrada, empezando por la mercantilización, el proceso de transformar el uso para intercambiar valor, siguiendo por la espacialización, la transformación del espacio con el tiempo, o el proceso de extensión institucional, y finalmente la estructuración, el proceso de constituir estructuras como resultado de la acción social". Para nuestro autor, repensar la Economía Política de la Comunicación, conlleva, entre otros parámetros:

- Desarrollar la concepción categórica con, en primer lugar, una visión relacional de la clase que la define de acuerdo a aquellas prácticas y procesos que relacionan las categorías de clase social.

—Equilibrar otra tendencia: cuando se ha prestado atención a la acción, proceso y práctica social, se ha tendido a centrarse en la clase social. Hay buenas razones para este énfasis. La estructuración de clase es un punto de entrada central para comprender la vida social y numerosos estudios han documentado la persistencia de las divisiones de clase en la economía política de la comunicación. A pesar de ello, hay otras dimensiones de la estructuración que complementan y están en conflicto con la estructuración de clase, incluyendo el género, la raza y los definidos ampliamente como movimientos sociales que, junto con la clase, constituyen muchas de las relaciones sociales de comunicación. La economía política ha hecho grandes progresos al dar cuenta de la intersección de los estudios feministas y la economía política de los medios

- Los economistas políticos de la comunicación documentan las formas a través de las cuales los medios masivos más importantes promueven la individuación y demuestran cómo estas acciones aíslan a los individuos de los demás, de sus identidades sociales y de clase, y de aquellos con el poder de llevar a cabo la individuación. Los economistas políticos también describen la forma en que algunos medios, aunque marginales, se resisten a participar en el proceso hegemónico de individuación y sugieren formas de expresión colectiva y democrática. (Mosco, 2006)

Desde el punto de vista de la acotación como disciplina, Mosco estima que "es útil situar a la economía política de la comunicación en oposición a los estudios culturales, por un lado, y la ciencia política, por otro". Lo que debe hacer la Economía Política de la Comunicación, según Mosco, es "repensar los estudios culturales". En este sentido, aclara: 
Aún asumiendo un planteamiento filosófico abierto a la subjetividad y más ampliamente inclusivo, la economía política insiste en una epistemología realista que conserva el valor de la investigación histórica, de pensar en términos de totalidades sociales concretas, con una filosofía moral bien asentada y un compromiso para superar la distinción entre investigación y práctica social. La Economía Política se aparta de la tendencia de los estudios culturales a exagerar la importancia de la subjetividad, así como de su inclinación a rechazar el pensar en términos de prácticas históricas y totalidades sociales. La economía política también se aparta de la tendencia de los defensores de los estudios culturales a utilizar un lenguaje poco claro, que contradice la visión original de este planteamiento de que el análisis cultural debería ser accesible a aquellos individuos ordinarios que son los responsables de crear cultura. Finalmente, evita la propensión presente en los estudios culturales a rechazar los estudios laborales y del proceso laboral en favor de examinar la "producción" social del consumo, y la tendencia resultante entre algunos de la escuela de los estudios culturales, a negar al trabajo cualquier valor en los movimientos contemporáneos de cambio social. (Mosco, 2006)

Por lo que se refiere a la relación de la Economía Política de la Comunicación con la política propiamente dicha, Mosco intenta delimitar la personalidad de su disciplina de la siguiente manera:

La Economía Política ha tendido a considerar al gobierno como demasiado dependiente de y determinado por la configuración específica del capital dominante en un momento determinado, y por tanto, se beneficia de un enfoque que considera seriamente el rol activo del estado. Además, la economía política comparte con la ciencia política el interés por extender el análisis al conjunto de la totalidad social, prestando también atención a la transformación social. Sin embargo, la economía política se aparta de manera fundamental de la tendencia de la ciencia política a un análisis político pluralista, que visualiza al estado como el árbitro independiente de un amplio equilibrio de fuerzas sociales, ninguna de las cuales tiene poder suficiente para dominar la sociedad. En contraste con ello, la economía política insiste en el poder del comercio y el proceso de mercantilización como el punto de partida del análisis social. Además, la economía política rechaza la tendencia de la ciencia política a construir su análisis de la totalidad social, y de aquellos valores que deberían guiar su transformación, sobre el individualismo y la racionalidad de mercado. En contraste con ello, insiste sobre los procesos sociales, partiendo de la clase social y el trabajo, y sobre el establecimiento de la comunidad y la vida pública en oposición al mercado y una racionalidad que, desde la perspectiva de la economía política, reproduce de hecho el poder de clase. (Mosco, 2006)

Lo que más nos interesa de las ideas de Mosco es su afán práctico-empírico, su deseo de apego a la realidad articulada y la necesidad de la claridad expositiva para huir de la abstrusidad como seña de identidad presuntamente científica. Sin embargo, desde el punto de vista del Enfoque Estructural Complejo (EEC) su delimitación de la Economía Política de la Comunicación nos resulta algo insuficiente, de ahí que prefiramos definir a esta ciencia con el nombre submetodológico estructural de Economía Política de la Información, la Comunicación y la Cultura (EPICC), de- 
pendiente de su matriz, el Pensamiento Transversal al que llevamos a la realidad mediante la Metodología del Enfoque Estructural Complejo (MENEC).

Si nos ceñimos a lo empírico, a la realidad, la EPICC puede ser demostrada y comprobada mediante las evidencias que nos muestran tanto la sociedad del siglo XXI en general como la crisis financiera que comienza en 2007-2008. Cinco conceptos entran en liza en la EPICC: Economía, Política, Información, Comunicación, Cultura. ¿Cómo se relacionan entre ellos?

Los presocráticos nos enseñaron a articular elementos y, por tanto, a ir más allá de las apariencias. En gran medida, de ellos bebemos aún, como se ha mostrado más arriba. Sus cuatro elementos — aire, tierra, fuego, agua - además de mantener una relación que ahora llamaríamos estructural, estaban a su vez compuestos por partículas más pequeñas e indivisibles: los átomos. Los siglos nos han mostrado que nuestros átomos son a su vez divisibles. Los presocráticos sentaron las bases del EEC y del origen de las distintas ciencias, algo que sería un poco más tarde ratificado y ampliado por Platón y Aristóteles (Sabine, 1974: 38 y ss.). Nos toca a nosotros ahora articular a nuestros cinco elementos, siempre sin perder la perspectiva de que nos hallamos en el seno de una hermenéutica transversal y compleja representada por el EEC.

Sin descender a mayores matizaciones por una necesidad de síntesis, las evidencias - por ejemplo, la creación de la Unión Europea (UE) o la crisis de 2007-2008 así como el papel de la llamada Troika (Comisión Europea/CE + Fondo Monetario Internacional/FMI + Banco Central Europeo/BCE) - demuestran que lo político o ha estado sometido a lo económico o, al menos, lo económico determinaba seriamente a lo político, poniendo en solfa la soberanía de los estados de la UE. Con otros nombres o con la presencia de alguno de ellos, el hecho puede ser visible en otras partes del planeta. He aquí a la Idea de Platón o al Ser inmutable de Parménides "corporeizado" en Troika.

Pero la Idea/Ser inmutable precisa de "cosas" mudables/mutables para seguir en su estado de aparente o teórica inmovilidad. Dichas "cosas" —necesarias para su autoconservación - se denominan estrategias mediáticas de información que se llevan a cabo mediante la actuación homogénea de grupos y/o corporaciones que poseen productos divulgadores de opinión: los medios de comunicación mercantiles que suelen actuar mediante el apoyo a las finalidades de la Idea/Ser/Mercado.

Dichas estrategias originan en el receptor reacciones por acción u omisión, es decir, provocan una interacción a la que llamamos comunicación que suele responder a las intenciones de las estrategias informativas (funcionalidad del mensaje). Por ejemplo, el miedo al caos y a lo nuevo, a las "improvisaciones políticas", al riesgo que conlleva lo novedoso (como nuevas corrientes políticas disidentes con la Idea) por lo general, logran objetivos favorables a la inmutabilidad esencial de la Idea/ estructuras de poder/mediáticas como hecho histórico.

Cuando la funcionalidad no resulta eficaz en la medida de lo deseado, la Idea segrega nuevas estrategias de "cosas", nuevas estrategias mediáticas y no mediáticas (lampedusianas) que reconduzcan la situación hacia la inmutabilidad de la Idea o hecho histórico Estructura. Un acto lampedusiano no mediático es, por ejemplo, un cambio en la forma de actuar del BCE como, de hecho, ha sucedido. La Idea genera sus propias necesidades, por consiguiente, y esta constatación desemboca por fuerza en el pensamiento de un filósofo alejado, cronológicamente, de los clásicos: Hegel, (2004: 59 y ss) de quien dejamos tan sólo apuntado ese principio. 
Toda esta dinámica la llevan a cabo las "cosas" mudables de Platón o el ser mutable de Heráclito sobre la base de unos factores culturales (propiedad privada, orden, paz, tranquilidad, progreso, valores éticos, simbólicos...) y emocionales que resultan ser también culturales (miedo, inseguridad, confusión, temor, atracción, repulsa, persuasión) que ya estaban ahí o que no estaban, que se refuerzan o se crean. No se tiene siempre garantizado el éxito de la inmutabilidad del Ser/Idea pero sí al menos una prolongación en el tiempo. Mientras más amplia sea la actuación en pro de la confusión, por ejemplo, más amplitud temporal poseerá la inmutabilidad de la Idea/Estructura.

La articulación - apresurada pero creemos que coherente - entre nuestros cinco elementos -Economía, Política, Información, Comunicación, Cultura - sobre la base de las aportaciones filosóficas clásicas está ya esbozada. Su aplicación práctica a la realidad europea — contexto vital de quienes firmamos este trabajo- no es más que un paradigma concreto pero exportable a otras realidades pasadas, presentes y futuras. Ahora hay que volver a insistir en que todo ello no es más que una submetodología de una metodología del Todo llamada por nuestra parte Metodología del Enfoque Estructural Complejo (MENEC).

\section{Conclusiones}

1. La persecución del entendimiento del Todo como acontecimiento/"noticia" desde el por qué periodístico, filosófico y científico conduce a la elaboración de una filosofía basada en la transversalidad del conocimiento, es decir, a la Metodología del Enfoque Estructural Complejo (MENEC) susceptible de ser parcializado sin perder de vista su esencialidad.

2. En concreto, preguntarse por la casuística de algo — sobre todo profundaexige adoptar un Pensamiento Transversal (PT) que debe concretarse en una Metodología del Enfoque Estructural Complejo (MENEC) para intentar alcanzar el máximo grado de Conocimiento Omnisciente (CO).

3. Este enfoque hunde sus raíces en los inicios de la Filosofía tal y como la estudiamos generalmente en el mundo occidental. Ello demuestra la indudable utilidad de la Filosofía como materia hermenéutica y de autoayuda.

4. La labor periodística — sin menospreciar su personalidad — queda incompleta si no se la enfoca en toda su profundidad, a partir de la EPICC — una parcela del ENEC - y del propio Enfoque Estructural Complejo.

5. No obstante, esta labor es posible y probable que quede reducida a estrechísimos círculos académicos y sociales. Sin embargo, sin ella el conocimiento completo y certero no puede producirse. Por tanto, la formación del universitario, del periodista, del comunicador, del ciudadano, queda limitada y, con ello, tal vez el valor mismo de la democracia porque estamos hablando de un conocimiento aplicado al progreso social.

\section{Referencias bibliográficas}

Arnaiz, Gabriel (2007): “¿Qué es la Filosofía Práctica?”. A Parte Rei. Revista de Filosofía, septiembre. Disponible en: http://serbal.pntic.mec.es/ cmunoz11/arnaiz53.pdf

Casals Carro, María Jesús (2005): Periodismo y sentido de la realidad. Teoría y análisis de la narrativa periodística. Madrid, Fragua. 
De Fontcuberta, Mar (1993): La noticia. Pistas para percibir el mundo. Barcelona, Paidós.

Descartes, René (1998): Discurso del Método/Meditaciones metafísicas. Madrid, Boreal.

Díaz, Ángel (2011): "Neurotransmisores. Respuestas al estrés. El cerebro se reorganiza cuando ve cine de terror", en www.elmundo.es, 24 de noviembre. Disponible en: http://www.elmundo.es/elmundosalud/2011/11/24/neurociencia/1322158308.html

Ferrés i Prats, Joan (IP) (2011): Competencia mediática. Investigación sobre el grado de competencia de la ciudadanía en España. Instituto de Tecnologías Educativas/Consell de l'Audiovisual de Catalunya/Comunicar. Disponible en:

http://ntic.educacion.es/w3/competencia_mediatica/competencia_mediatica.pdf

Harris, Marvin (2000): Teorías sobre la cultura en la era posmoderna. Barcelona, Crítica.

Hawking, Stephen W.(2009): The Theory of Everything. London, Phoenix Books and Audio.

Hegel, Georg Wilhelm Friedrich (2004): Lecciones sobre la filosofia de la historia universal. Madrid, Alianza Editorial. Prólogo de José Ortega y Gasset.

Heráclito et al. (1999): Textos presocráticos. Barcelona, Edicomunicación.

Herrero Aguado, Carmen (1991): "Filosofía de la Comunicación", en Benito, Ángel (director): Diccionario de Ciencias y Técnicas de la Comunicación. Madrid, Paulinas.

Jaspers, Karl (1994): Origen y meta de la historia. Barcelona, Altaya.

López Facal, Javier (2011): "Entre Demócrito de Abdera y Peter Higgs", en El País, secc. Opinión, 14 de diciembre. Disponible en:

http://sociedad.elpais.com/sociedad/2011/12/14/actualidad/1323876601_989336.html

Lorenz, Konrad (1974): La otra cara del espejo. Barcelona, Plaza \& Janés.

Mancinas-Chavez, Rosalba (2008): El poder mediático en México: relaciones entre economía, política y medios de comunicación. Grehcco/Universidad de Sevilla.

Marx, Karl (1989): Contribución a la Crítica de la Economía Política. Moscú, Progreso. Disponible en:

https://gnoseologia1.files.wordpress.com/2011/07/marx-carlos-contribucion-a-la-criticade-la-economia-politica1.pdf

Marx. Karl y Engels, Friedrich (2005): El Manifiesto Comunista. Disponible en: http:// dspace.universia.net/bitstream/2024/1507/1/marxengels_manifiestocomunista.pdf

Morin, Edgar (2006) El método. I. Madrid, Cátedra. Disponible en: http://dspace.universia. net/bitstream/2024/1345/1/el_metodo_1.pdf.

Mosco, Vicent (2006): “La Economía Política de la Comunicación: una actualización diez años después". CIC Cuadernos de Información y Comunicación, 2006, vol. 11 57-79.

Mosco, Vicent (2009): The Political Economy of Communicaton: Rethinking and Renewal. Los Angeles/London, Sage.

Muñoz, Blanca (2005): Cultura y comunicación: introducción a las teorías contemporáneas. Madrid, Fundamentos, $2^{\mathrm{a}}$ edición.

Murdock, Grham \& Golding, Peter (2000): "Culture, Communications and Political Economy”. In Curran, James \& Gurevitch, Michael (eds.): Mass Media and Society (Third Edition). London, Arnold, pp. 70-92.

Nogales-Bocio, Antonia Isabel (2015): La creación y proyección del concepto de individuo en la cultura de masas contemporánea. Perspectiva filosófica y análisis de discurso mediático. Trabajo Fin de Máster, Máster Oficial en Filosofía y Cultura Moderna, Universidad de Sevilla, Inédito.

Pena de Oliveira, Felipe (2006): Teoría del Periodismo. Sevilla, Comunicación Social Ediciones y Publicaciones.

Pérez Mercader, Juan (2000). ¿Qué sabemos del universo? De antes del big bang al origen de la vida. Barcelona, Debate. 
Pérez-Lanzac, Carmen (2013). “Mucho Facebook, ¿poca concentración?”, El País, 10 de noviembre. Disponible en: http://sociedad.elpais.com/sociedad/2013/11/10/actualidad/1384115247_184450.html. [Consulta: 15 de noviembre de 2015].

Popper, Karl (1995): Lógica de la investigación científica. Madrid, Círculo de Lectores.

Punset, Eduardo (2012): El alma está en el cerebro. Barcelona, Destino.

Reig, Ramón (1995): El control de la comunicación de masas. Bases estructurales y psicosociales. Madrid, Libertarias/Prodhufi.

Reig, Ramón (1999): ¿De la caverna prehistórica a la caverna cibernética?: reflexiones sobre la nueva era de la información". Revista Anthropos. Huellas del conocimiento, núm. 186, 81-90. Monográfico Semiótica crítica. De la historia del sentido al sentido de la historia. Barcelona. Reig, Ramón (2001): El éxtasis cibernético. Madrid, Libertarias/Prodhufi.

Reig, Ramón (2010): La telaraña mediática. Zamora/Sevilla, Comunicación Social Ediciones y Publicaciones.

Reig, Ramón (2011a): Todo Mercado. Contra la simplicidad del pensamiento crítico. Barcelona, Anthropos.

Reig, Ramón (2011b): Los dueños del periodismo. Claves de la estructura mediática mundial y de España. Barcelona, Gedisa.

Rivera, Alicia (2012), “La partícula de Higgs por fin!”, El País, 4 de julio, secc. Sociedad. Disponible en:

http://sociedad.elpais.com/sociedad/2012/07/04/actualidad/1341384264_933365.html.

Rodrigo Alsina. Miquel (1989): La construcción de la noticia. Barcelona, Paidós,

Sabine, George (1974): Historia de la teoría política. Madrid/México, Fondo de Cultura Económica.

Sánchez-Bravo Cenjor, Antonio (1992): Manual de Estructura de la Información. Madrid, Fundación Centro de Estudios Ramón Areces.

Schiller, Dan (1999): Digital Capitalism. Cambridge, MA, MIT Press.

Vilar, Pierre (1981): Iniciación al vocabulario del análisis histórico. Barcelona, Crítica.

Ramón Reig es Catedrático de Estructura de la Información en la Universidad de Sevilla (Departamento de Periodismo II, Universidad de Sevilla). Sus principales líneas de investigación son estructura y políticas de comunicación, análisis del discurso periodístico, poder y medios de comunicación y pensamiento complejo. Algunas de sus principales publicaciones son: Crisis del sistema, crisis del periodismo (2015), Educación para el Mercado (Director, 2013), Los dueños del periodismo (2011), Todo Mercado (2011), La telaraña mediática (2010), El periodista en la telaraña (2007), Dioses y diablos mediáticos (2004), entre otros.

Rosalba Mancinas-Chávez es doctora en Periodismo por la Universidad de Sevilla, Licenciada en Ciencias de la Información por la Universidad Autónoma de Chihuahua (México). Es profesora en el Departamento de Periodismo II de la Universidad de Sevilla y del Centro Universitario EUSA. Ha publicado El poder mediático en México (2008), Educación para el Mercado (Coordinadora, 2013), Medios de comunicación y cambio climático (coordinadora, 2012)., además de artículos en diferentes revistas académicas. 
Antonia I. Nogales-Bocio es licenciada y doctora en Periodismo por la Universidad de Sevilla. Profesora en el Centro Universitario EUSA (adscrito a la Universidad de Sevilla). Coordinadora de la obra Emprender en femenino en Comunicación (2014), ha publicado en revistas como Revista Latina de Comunicación Social (España), Razón y Palabra (México) y Correspondencias \& Análisis (Perú), entre otros. 